\title{
Almodóvar y la política Trans. Notas a pie de página
}

\author{
La mala educación | Pedro Almodóvar | 2004 \\ Martin De Mauro Rucovsky* \\ CONICET - Ciffyh
}

Recibido: 26 de mayo 2016; aprobado: 08 de julio 2016

\begin{abstract}
Resumen
El presente recorrido, a través de notas y comentarios, propone una reinterpretación (acaso oblicua) de la obra del español Pedro Almodóvar, "La mala educación” estrenada en 2004. El filme escenifica no solo una historia anticlerical (o al menos no se reduce a este tópico exclusivamente) tal como señalara el mismo Almodóvar. La trama de la película pone en guerra un ordenamiento de cuerpos atravesada por los mecanismos de poder clericales, y el universo que construye desde ahí tematiza una violencia ulterior dirigida a un cuerpo trans. Para circunscribir la singularidad de estos interrogantes diremos que "La mala educación" entabla una suerte de economía de la violenciasobre una economía del deseo en el marco de un registro cinematográfico que no deja de reinscribe en las representaciones necropolíticas sobre cuerpos Trans.
\end{abstract}

Palabras clave: Pedro Almodóvar| Trans | necropoder | capitalismo gore

Almodóvar and Trans politician. Footnotes page

\begin{abstract}
This trail proposes a reinterpretation, through a oblique read, of the Spanish movie 'Bad Education' from Pedro Almodóvar, released in 2004. The film stages not only an anticlerical story but also a regulation of bodies crossed by the mechanism of the clerical power. From there, the film builds a universe that thematized a subsequent violence address to a particular Trans body. To circumscribe these questions, we will say that Bad Education establishes an economy of violence through a economy of desiere in the context of a cinematography registry that re-enroll in the necropolitic representation of Trans bodies.
\end{abstract}

Key words: Pedro Almodóvar| Trans | necropower | gore capitalism

Ella se define a símisma como una mezcla de desierto, casualidad y cafetería Paquito (Javier Cámara)

1. ¿Cuáles son aquellas características que atribuimos como efecto de mirada y lectura a "La mala educación" (2004) y en particular cuales son los gestos cinematográficos que vinculamos a Almodóvar escritor, guionista y director?

2. En este mismo sentido, ¿qué es aquello que por oposición ética es la mala educación frente a una buena educación? Si toda educación es una espacialidad que supone un ámbito de la no-educación y por lo mismo una positividad de lo educado (una subjetividad de lxs educadxs), la pregunta por las condiciones de posibilidad de la mala educación esbozan también los límites de una buena educación posible. De allí la contemporaneidad de la pregunta como interpelación a un presente: ¿Cuál es nuestra buena y mala educación hoy, en nuestro tiempo presente, contemporáneo?

3. Ejercicio hermenéutico o efecto de lectura sobre la película: pensar algunos puntos de fuga quizás tematizados pero de un modo oblicuo. Para circunscribir la singularidad de estos interrogantes diremos que "La mala educación" entabla una suerte de economía de la violencia sobre una economía del deseo.

4. A primera vista la mala educación no es una historia anticlerical simplemente (o al menos no se reduce a este tópico exclusivamente) tal como señalara el mismo Almodóvar. "La mala educación" funciona a partir de un registro otro. Es, pues, el deseo y el goce lo que la película interroga a partir de la mirada y su encuadre respectivo Aquí deberíamos incluir dos (sub)registros: de un lado, la mirada entendida como régimen de visibilidad que nunca es acabado ni absoluto (monoteísmo de la mirada:

molotov108@gmail.com 
el ojo de Dios). Antes bien, siguiendo al par ${ }^{2}$. Hay que pensar esto en términos de un esbozo cinematográfico sobre el espacio y la legalidad tempestiva del deseo "un terreno árido, descarnado, visceral, rico en secretos" señala el director ${ }^{3}$.

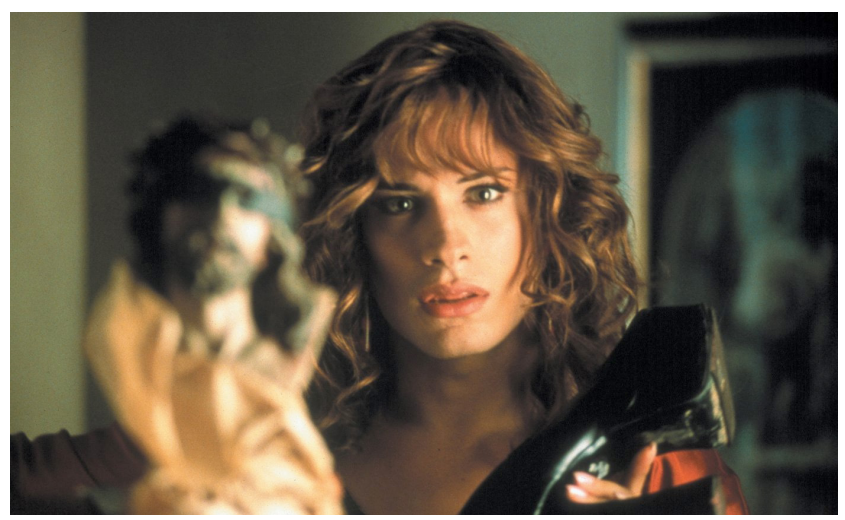

Entonces, no se trata solamente de una dislocación a nivel del deseo, sino que ese pliegue será entonces el campo de lo nombrable y lo figurable a lo largo del film. Ese desplazamiento en el registro del deseo ${ }^{4}$ es, justamente, aquello que no se opone al orden religioso como tal, no obstante, vale decir, lo religioso se constituye como su condición de posibilidad. La subjetividad sexual y genérica aparece tempranamente mediada por el discurso, las prácticas y las jerarquías sexuales etarias (en términos jurídico-patológicos, la pedofilia). La trama de la película pone en guerra un ordenamiento de cuerpos atravesada por los mecanismos de poder clericales, y el universo que construye desde ahí tematiza unaeconomía de la violencia dirigida a un cuerpo trans en particular. A la vez, la potencia crítica de este artefacto cinematográfico pasa por los deseos, tópicos, gustos y cuerpos de alta carga homoerótica.

5. La película cuenta con un complejo sistema de citas, detalles, guiños y paratextuales. Al menos se traman tres historias paralelas y la filmación de la propia película en, lo que podría constituir, un giro metonímico de autorreferencia. Un ejemplo no del todo anecdótico, lo constituye la imagen de la parca encarnada en una anciana que camina en contiguo a Enrique (Fele Martínez) cuando este se sube a su coche, en el contexto de su visita a la casa natal de Ignacio (Francisco Boira). Apenas un gesto sutil que intensifica el clima mortuorio y misterioso que ronda la muerte de Ignacio en la ciudad natal de éste (algún poblado de Galicia). Es así que Almodóvar en el diario de la filmación señala que se trata de versiones dentro de la propia película, recurso estilístico al microrrelato dentro de la estructura narrativa general. La película se cita a sí misma en una parábola que agrega circularmente información en una narrativa que vuelve sobre sí.

5. Una premisa orienta las lecturas que componen el presente: un tópico transversal que sigue toda la narrativa de "La mala educación" y muchos otros films de Almodóvar (como) son los vínculos homoeróticos, el deseo y el goce como potencias afectivas desbordantes y los cuerpos generizados como masculinidades-feminidades varias. Es así que en "La mala educación" podemos leer, no sin un esfuerzo de agudeza, en un intersticio que está atravesando la intensidad del suspenso narrativo, una realidad corporal poco común a la norma social hegemónica: la trans ${ }^{5}$. Entendiendo por ello la referencia simultánea a transexuales, transgéneros y travestis ${ }^{6}$. Y no es sino a través de la homoerotización del deseo y la pasión como se tematiza la corporalidad trans. En esta película la homosexualidad se hace visible no sin una incomodidad que deviene violencia educativa y religiosa y por lo mismo es incómoda al devenir trans de uno de los protagonistas. Si el salir del Closet (del armario social heterosexual) de Enrique es de por sí mismo conflictivo y violento a la institución pedagógica, algo similar ocurre con el proceso de autoafirmación trans que supone también una violencia social encarnada. De acuerdo al propio Almodóvar como intérprete e interlocutor, la película trata de masculinidades, del tempestuoso terreno del deseo (y habría que agregarle) del deseo homomasculino. En este sentido la cuestión trans aparece como el reverso homosexual, esto es, el devenir de un cuerpo masculino marcado como tal.

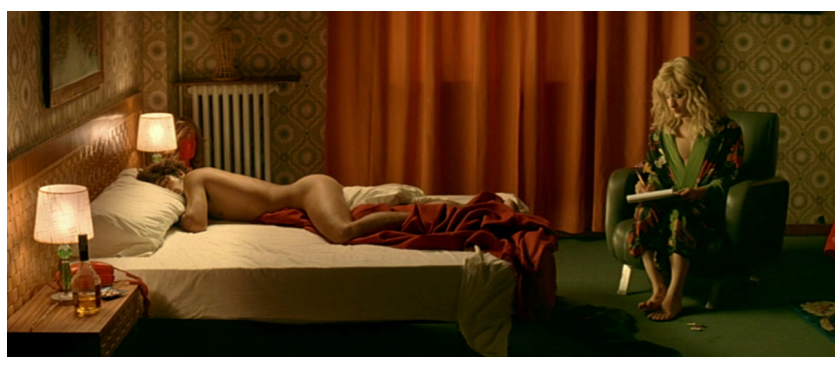

Lo que se trasluce entonces, lo que se corre del centro (no sin violencia discursiva) es la realidad trans que se produce en este reverso homoerótico. Es justamente por esta operación que el cuerpo trans de Enrique pierde densidad como tal, la subjetividad de éste se ve opacada en todo caso por el vínculo Manuel (Lluís Homar) - Juan (Gael García Bernal) (cura-hermano) o en todo caso por la estetización idealizante del propio hermano (Juan o Ángel Andrade) y el director del film (Enrique).

6. Economía de la violencia. La película trata de un cri- 
men sobre una persona trans. Como señala Mauro Cabral a propósito de la psicoanalista Irene Meler, se trata de "esa articulación entre el hacer propio y el deseo del otro", una articulación por cierto violenta y homicida en principio. Donde el hacer propio de Juan, en su vínculo parental con Ignacio y su madre, así como el vínculo no exento de plusvalía mercantil y chantaje entre este y el Sr. Berenguer (padre Manuel) lo que en consecuencia redunda en la privación del deseo de Ignacio. La tópica trans se produce en estos vínculos homoparentales, sea Angel Andrade-Enrique, sea en la relación educativa inicial entre Ignacio y Enrique o el ya mencionado vínculo Juan-Berenguer. Un cuerpo y una realidad que carece de propia densidad, es una subjetividad que se produce desde el deseo del otro, donde lo mismo y el centro son vínculos homosexuales. Y desde allí se lee la película, en su lectura más canonizada, esto es, desde la visibilidad homosexual y no en cambio como un thriller de suspenso anclado en la muerte fatal y violenta de una persona trans.

7. Operación Almodóvar. Justamente en esta impropiedad de la transexualidad que se corre del centro es donde la estetización de Ignacio salda sus cuentas. Es en la imagen Juan-Ángel Andrada haciendo las veces de Sahara Montiel (Gael García Bernal) donde se acciona aquel entramado enunciativo de la estetización trans. La operación Almodóvar será entonces la estetización de los cuerpos trans ${ }^{7}$ en una imagen de belleza corrida, una repetición desviada en tanto montaje, en tanto performance de género y de parodia o ridiculización del objeto venerado, de allí sus vínculos con una pose $\operatorname{Camp}^{8}$. Sahara Montiel como encarnación de Ignacio tanto en el ideario de Juan-Angel y de Enrique director no es más que la estetización (como cuerpos bello y extravagante) de un cuerpo trans que es incómodo en todo sentido. Es así que la operación Almodóvar curiosamente supone una visibilidad excluyente de lo transgénero, de tanta exposición deviene anestesia a los sentidos, de sobreexposición se produce la habituación inclusive de deseos tempestuosos (no heteronormativos y queer).

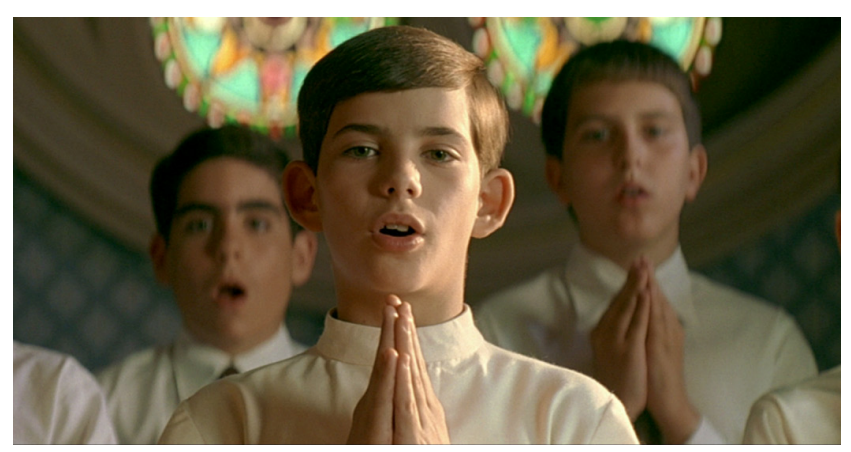

Como lo señalara Simone de Beauvoir "lo más escandaloso que tiene el escándalo es que uno se acostumbra”. Si la temática gay es el centro narrativo e interpretativo de Almodóvar, lo trans solo figura a modo de excentricidad estética o fetiche abyecto que intensifica la transgresión cinematográfica de su figura pública. Si de algún modo lo trans figura en nuestro universo de lo nombrable, deseable, pensable, significable e imaginable es de por sí un espacio fallido como si fuese una genealogía tachada a priori. En este sentido las presentes notas y lecturas se inscriben (por contingencia y fuerza política) en un específico campo de batallas, es decir un contexto histórico concreto: la inclusión de una mención no patologizante y la retirada de la categoría de "disforia de género" - "trastornos de la identidad de género" de los catálogos diagnósticos DSM V (de la American Psychiatric Association) y CIE-11 (de la Organización Mundial de la Salud) ${ }^{9}$.

Si la tachadura a estas subjetividades responde a criterios estéticos y políticos tal como se producen en este mismo film, algo semejante ocurre en cuanto a la dogmática psicológica y psiquiátrica con su ejército de patologías sociales. La existencia de vidas en términos de diagnóstico muestra la brutalidad del orden psiquiátrico (como vector social disciplinante y normalizador) frente a un universo sexual posible que se ve reducido al binomio más estándar (masculino o femenino).

8. No podemos menos que leer "La mala educación" a contrapelo de los tiempos que corren. Poco antes de la sanción de la Ley de identidad de género en Argentina ( $\left.\mathrm{N}^{\circ} 26743\right)$, y en sintonía con la aprobación del matrimonio igualitario en EEUU el pasado 26 de junio de 2015, un sinnúmero de materiales culturales no han dejado de visibilizar e incluir a personas Trans 10. Se trata de una representación canonizada y una recurrencia temática producto de la industria cultural (local y global) que, una vez más, funciona sobre una lógica extractivista (Colectivo Juguetes Perdidos, 2014, p. 155) o de colonización de experiencias (Radi, 2015; Cabral, 2009) trans. Pareciera que el precio a pagar, de esta suerte de nueva fetichización de las prácticas sexuales, identidades, cuerpos, biografías y experiencias trans, es la objetualización de sus vidas, la captura por el dispositivo en vistas de la extracción de algún tipo de plus valor estético-político.

De otro modo, el dispositivo cinematográfico reproduce en su interior la cuestión trans como índice del llamado necropoder o capitalismo gore (Valencia, 20102012), como modalidad del capitalismo contemporáneo en tiempos neoliberales que altera la lógica del proceso 
de producción del capital (mercancías que tienden a la espectralidad del mercado financiero). En el capitalismo gore este proceso solo es posible a través de la producción y gestión política de cuerpos muertos, mutilados o vejados como forma de capital acumulable (Valencia, 2010 y 2012). Y esto ocurre como una modalidad precisa de gubernamentalidad necropolitica o lógica zombiopolitica (Platzeck, 2015) en donde las vidas y poblaciones trans aparecen marcadas desde el principio como socialmente muertas (De Mauro Rucovsky, 2015). Entonces, el dispositivo cinematográfico reproduce un vector de poder y de racionalidades diversas que acumula capital a través de la muerte social de poblaciones especificas, gestión y destino de cuerpos trans.

Frente a este escenario le anteponemos la sospecha: ¿de qué modo se narran las vidas Trans? ¿Quién narra, escribe y guiona estas vidas? ¿Para quién y bajo qué presupuestos? ¿Qué mirada sobre lo trans se configura?
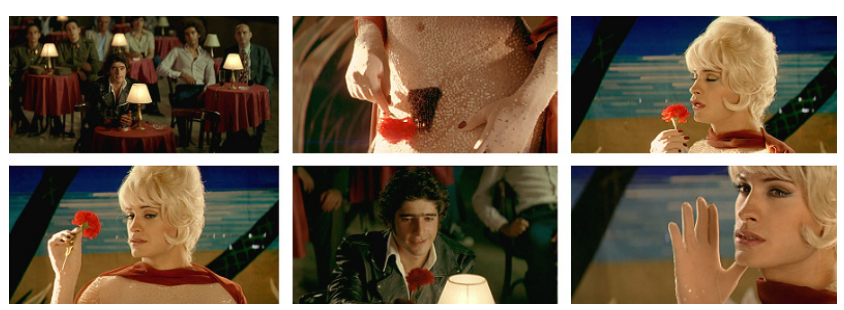

Y vale recodar la película "La piel que habito", dirigida también por Pedro Almodóvar en 2011, su mirada hiperesteticista sobre las corporalidades Trans:

¿Por qué es tan reticente la industria del cine a contratar a actrices trans para papeles trans? ¿Queremos ser "la travesti de la novela" y cagarle el laburo a la otra contendiente, o queremos espacio para actuar, dirigir y escribir guiones de todo tipo como profesionales competentes? (Bennet, 2016).

Frente a ello, conviene recordar, a modo de advertencia ético-metodológica, lo dicho por Lohana Berkins en Harvard Law School el 5 de abril de 2010: "Con todo respeto, yo no soy Rigoberta Menchú, yo no vengo sólo a hablar de cuan víctimas somos las personas trans en la Argentina. Yo no vengo a esta universidad a dar testimonio, yo vengo a discutir teoría”. (Berkins \& Fernandez, 2005).

Como espacio vacío y al modo de una subjetividad e identidad espectral, la transexualidad es un hipótesis de lectura en sí misma im-posible. Porque en el eje interpretativo, en las lecturas desde la cual vemos el film, el crimen homicida a una persona trans está en segundo plano, se trata en todo caso de un thriller de suspenso en donde el deseo masculino está en juego. Si por contrario hacemos de esta una lectura posible entre otras, y abogando por la politicidad propia del discurso como fuerza, lo que queda no será la paz de una única lectura (su clausura de sentidos), por contrario le opondremos otra fuerza, de allí el campo de batallas hermenéutico que hemos abierto (la proliferación de los mismos). Y haciendo de Almodóvar una caja de herramientas podemos reencontrar un gesto recurrente en estos materiales: el que suspende distinciones normativas entre sexo, género, deseo y órdenes normativos. Más aun, la cuestión trans es visibilizada y al mismo tiempo queda opacada en la obra de Almodóvar bajo la jerarquía cisgénero ${ }^{11}$.

No obstante, como sabemos, las capas narrativas son múltiples, cóncavas y convexas. De allí que puede leerse toda una hermenéutica tan camp como queer ${ }^{12}$ configura a partir de los distintos registros que Almodóvar construye.

\section{Referencias}

Bennett, K. (12 de Febrero de 2016) “El Star CIStem”. Artículo aparecido en suplemento Soy (diario Página 12) el Viernes 12 de Febrero de 2016. Version on-line disponible:http://www.pagina12.com.ar/diario/suplementos/soy/1-4393-2016-02-12.html http:// www.pagina12.com.ar/diario/suplementos/soy/1-4393-2016-02-12.html (consultado 24/5/16)

Berkins, L. y Fernandez, J. (2005) La gesta del nombre propio. Informe sobre la situación de la comunidad travesti en la Argentina. Buenos Aires: Ed. Madres de Plaza de Mayo. Butler, J. (2002) Cuerpos que importan: sobre los limites materiales y discursivos del "sexo". Buenos Aires: Paidós.

Butler, J. (2010) Marcos de guerra: las vidas lloradas. Buenos Aires: Paidós.

Cabral, M. (2009) “Salvar las distancias. Apuntes acerca de Biopolíticas del Género” en AAVV. Biopolitica. Buenos Aires: Ají de pollo.

Cabral, M. (2012) “Algo ha pasado" en Sexualidades, desigualdades y derechos. Reflexiones en torno a los derechos sexuales y reproductivos. Faunes, Ruata, Vaggione (edits). Cordoba: Ciencia, derecho y sociedad edit.

Colectivo Juguetes Perdidos (2014) ¿Quién lleva la gorra? Violencia, nuevos barrios, pibes silvestres. Buenos Aires: Tinta y Limón. Derrida, J. (2011). El tocar, Jean-Luc Nancy. Buenos Aires: Amorrortu. (Versión original 2000).

De Mauro Rucovsky, M. (2016) Cuerpos en escena. Materialidad y cuerpo sexuado en Judith Butler y Paul B. Preciado. Madrid: Egales. 
De Mauro Rucovsky, M. (2015) “Trans" Necropolitics. Gender Identity Law In Argentina” enSexualidad, salud y sociedad, Revista Latinoamericana, n.20 - Agosto 2015 - pp. 10-27 ISNN 1984-6487, Rio de Janeiro, Brasil. Version on line: http://www.e-publicacoes.uerj.br/index.php/SexualidadSaludySociedad/article/view/9359/13340

Garcia, G. (2002) "No hay regulación política del goce”. Artículo aparecido en revistaRamona N²1-22, Marzo de 2002, Buenos Aires. Versión on-line disponible en:http://www.ramona.org.ar/files/r21-22.pdf http://www.ramona.org.ar/files/r21-22.pdf (consultado $24 / 5 / 16$ ).

Misse, M.y Galofre, P. (2015) Politicas Trans. Una antoloogia de textos desde los estudios trans norteamericanos. España: Egales

Misse, M. (2013) Transexualidades. Otras miradas posibles. España: Egales

Misse, M. y Coll-Planas, G. (2010) El género desordenado. Criticas en torno a la patologizacion de la transexualidad. España: Egales Nancy, J.-L. (2006). El intruso. Buenos Aires: Amorrortu. (Versión original 2000).

Nancy, J.-L. (2003). Corpus. Madrid: Arena. (Versión original 1992).

Platzeck, J. 2015. “Zombiopolitica”.On line Revista Caja Muda N 8. . Versión en linea disponible: https://issuu.com/cajamuda/ docs/numero_8/1 (consultado 26/5/16).

Radi, B. (2015). "Defundamentos y postfundaciones. Revoluciones conservadoras y tecnologías de apropiación de subjetividades trans en la obra de Beatriz Preciado”. EnSexualidad, Salud y Sociedad. Revista Latinoamericana. CLAM, No 20, 2015. Versión en linea disponible: http://www.e-publicacoes.uerj.br/index.php/SexualidadSaludySociedad/index (consultado 26/5/16)

Sontag, S. (2008) "Notas sobre lo camp". Artículo aparecido en Contra la interpretación y otros ensayos. Buenos Aires: Sudamericana.

Valencia, S. 2010. Capitalismo gore. Madrid: Melusina

Valencia, S. 2012. “Capitalismo gore y necropolítica en el México contemporáneo.”

Revista Relaciones Internacionales. Madrid: Universidad Autónoma de Madrid

Zizek, S. (1992) El sublime objeto de la ideología. Mexico: S.XXI.

1 A modo de sinopsis, el film puede resumirse del siguiente modo: "Enrique Goded es un famoso director de cine que recibe la visita de un extraño en su oficina, un actor en busca de trabajo, que afirma ser su compañero de colegio y primer amor. "Ignacio", su compañero, que ahora quiere ser llamado Ángel, ha escrito una historia sobre ambos, su vida en el colegio católico y los abusos físicos y sexuales que sufrieron a manos del padre Manolo, que incluye un final ficticio sobre su reencuentro después de esos años. El interés crece y Enrique decide hacer la película con Juan en el papel de Zahara, Ignacio en su madurez, para descubrir qué esconde. Enrique e "Ignacio" comienzan una relación y terminan el guion de la película: Zahara" (Wikipedia, consultado 24/5/16).

2 Nancy-Derrida $(2003,2006,2011)$ se trata de un régimen de visibilidad (monocular) que desplaza la unicidad de la mirada (un cruce de miradas o más aun: todo mirar tiene un punto ciego). De otro lado, el encuadre (marco/frame/párergon) tiene que ver con aquella operación que marca, separa y distingue un adentro de un afuera, un borde o contorno que encuadra un contenido, una obra. El encuadre cinematográfico es, vale decirlo, un marco de inteligibilidad que supone una ilusión de transparencia y neutralidad, solo se trata de "hacer visible", "mostrar" y "reflejar del modo más directo posible”. Antes bien, el marco cinematográfico combina, una política de la mirada y por lo mismo, una estructura afectiva-sensitiva-perceptiva (Cfr. Butler, 2010)

3 Nos referimos a las declaraciones en la página oficial de la mala educación. Véase "Comienzo del Rodaje: de mi puño y letra" en http://www.lamalaeducacion.com yhttp://www.pedroalmodovar.es/ (consultado 24/05/16)

4 Eso que Lacan llama goce, en sus distintas acepciones (goce fálico, goce del otro, Otro goce, plus-de- goce) remite aquí, a una variación o una línea de errancia respecto del goce en referencia al cuadro edipico tradicional. El goce de Zahara-Ángel-Ignacio es excesivo y frenético, lo que lo ubica en un espacio desencajado entre límite y exceso, falta y plus. Hay una potencia singular que La mala educación apenas esboza, y quizás convenga desarrollar, que hace del goce un ejercicio disruptivo y de suspensión sistemática del orden heteropatriarcal asociado al falogocentrismo.. Pero además este goce se instituye como modalidad de agenciamiento politizante o al menos delimita la pregunta: ¿̇es posible entender el goce, este goce, como modalidad de agenciamiento en los términos de una expresión (no traumática pero si dramática) del deseo? ¿Cómo se hace, como se produce un cuerpo individual, a qué precio y sobre qué gramática de dominación del par goce-deseo?.

5 Para abordar aquello que entendemos por norma social hegemónica conviene revisar la noción de cisgeneridad: Por cisexualidad o cisgeneridad nos referimos a las fronteras de la diferencia sexual que dividen todas las identidades y expresiones de género entre trans y no trans. La distinción entre hombres y mujeres y personas transexuales funciona sobre una lógica de distribución que privilegia el primer conjunto, mientras que desconoce al segundo (o lo reconoce bajo el imperio de una cópula menor). Una explicación simple se refiere al género identificado al nacer, si un" se identifica con éste, es una persona cisexual. Invirtiendo la carga de la prueba, la cisexualidad denota a aquell"s que carecen del atributo de ser trans (transexuales, transgéneras, travestis, cross dressers, no géneros, multigéneros, de género fluido, gender queer y otras autodenominaciones relacionadas).

$6 \quad$ Al hablar de personas trans", haremos referencia a todas aquellas personas identificadas con un género distinto al designado al 
nacer. En Argentina, el termino trans" despliega una triple enumeración, que da cuenta de colectivos diferenciados a nivel experiencial, pero sobre todo político, travestis, transexuales y transgeneros. La utilización del sintagma trans" no agota el universo de diferencias y posibilidades que constituye el universo trans". La escritura del término acompañado por un asterisco procura dar cuenta de la incompletitud del término. Cfr Cabral (2012).

7 Tal como ocurrirá en La Piel que habito estrenada en 2011, lo que constituye el paroxismo de este modo de mala educación en Almodóvar.

8 Sin hacer mención explícita a S. Sontag (2008) en sus ya canónicas “Notas sobre lo Camp”, podemos señalar que se trata de una imitación desviada, una parodia kitsch de aquello que más se venera, una glamourización de lo trash y la basura elevada a primera categoría, entre el original y la copia se produce esta imitación (mímesis) corrida de lugar, en este y en otros sentidos performativos consiste lo camp como gesto irreverente y provocador.

9 Puede referirse material en: http://www.stp2012.info/old/es (consultado 24/5/16) y Misse (2013).

10 Solo por mencionar algunas producciones recientes: La viuda de Rafael (serie emitida en 2012), la película Mía (dirigida por Javier van de Couter, estrenada en 2011), Andrea. Un melodrama Rioplatense (2013), Orange is the new Black (emitida por Netflix desde 2013), Sense 8 (de Lilly Wachowski en 2015-2016), la serie Transparent (desde 2014) y la celebrada La chica Danesa (de Tom Hooper en 2015).

11 Para una definición de cisgenero o jerarquía cisgenero véase nota 5.

12 que se La denominada teoría cuir o queer theory hace referencia a la resignificación del insulto y la injuria del término (en ingles desviado, maricón, marica, pervertido o tarado) por parte de grupos de activistas gays, lesbianos, trans e intersex en los años 80' en Estados Unidos e Inglaterra (los más conocidos Queer Nation, Radical Fury o Lesbian Avengers) que en disidencia contra las políticas asimilacioncitas y sus demandas de integración, toman la calle y utilizan el lenguaje del agravio para reivindicar la nominación como lugar de acción e identidad política. Cfr. Butler (2012:313). 